\title{
Narrative practices in restorative
}

\section{justice}

\section{J udit Hajdu}

\section{Abstract}

This paper gives a description of methodologies, practices and principles of narrative practices and an overview of restorative practices as a foundation for a suggested combination of the two approaches in dealing with criminal incidents. It notes similarities between the two approaches, including the importance of stories, involvement of communities and individuals in their own conflicts, rejection of blame, searching the broader social landscape for explanation and influence and acknowledging and accepting contradictory stories. The author sees the two movements as coming from different directions but occupying overlapping territories and identifies - two areas where combined use of the two approaches could be beneficial - at the interface between restorative justice and the courts and in the role of communities in restorative justice practice. It concludes with an invitation to practitioners to test the ideas for cross-fertilisation outlined in the article and to develop programmes that draw from both sets of practices for the benefit of victims, offenders and communities.

\section{Introduction}

I had been practising Narrative Therapy for families and couples and doing divorce mediations for a few years when I started working with prisoners and first encountered restorative practices. I was immediately struck by similarities between narrative methods and restorative practices and was sure I would see a great deal of liaison between them. To my surprise, I have encountered few instances of inclination to consider co-operation among narrative practitioners, 
and almost none in the field of restorative justice. As I started my training in restorative practices, I often felt an urge to include the well-structured scaffoldings of questions and interviews so characteristic of narrative practices into our exercises, and found they fitted in well even though they were not familiar to my tutors. I was encouraged to explore the possibilities of utilising a synthesis of restorative and narrative practices in criminal cases.

The acceptance and use of restorative and narrative practices have been gaining ground over the past few decades and the principles and methodologies of each method are becoming well-established. In primary and secondary schools, as well as in higher education, the two approaches have been usefully blended (Winslade and Kecskemeti, 2016; Winslade and Williams, 2012; Kecskemeti, 2013; Kecskemeti, et al., 2013; Ganem and Duncan, 2017; Walgrave, 2011) and it is my belief that the two practices could gain considerably from a more extensive alliance in other areas, especially criminal justice.

\section{Narrative practices - some history and areas of use}

Narrative therapy was developed by David Epston of New Zealand and Michael White of Australia in the 1980s (White and Epston, 1992; Denborough, 2008; Denborough et al., 2008). Their collaboration was rooted in anthropology, family therapy and Eriksonian hypnotherapy and created not only a new approach but a new paradigm in psychotherapy and, ultimately, in mediation and collective practices.

Narrative approaches, as will be discussed in more detail later, have always viewed individuals in relation to their social environment. Narrative practitioners work extensively with communities that endure hardship or have experienced trauma and in a close collaboration with them they have designed collective narrative practices that have been used effectively all over the world - for example, among prisoners, refugees, war survivors and other trauma victims (Denborough, 2008; Denborough et al., 2008). Mediation has also been developed 
in narrative practices to influence family counselling, divorce mediation and conflict resolution in health and educational settings (Winslade and Monk, 2000).

\section{The narrative metaphor}

Breaking away from the prevailing psychotherapy practices, narrative therapy does not assume an underlying dysfunction that defines the behaviour of people, but is concerned with the meaning-making processes, the way people organise events of their lives into stories and the way, in turn, these same stories determine their actions (White and Epston, 1990).

When people come to therapy they are usually not content with their stories. They do not want to continue to live their lives in line with them. Their problems are overwhelming and control their lives. They live problem-saturated stories.

The task of the narrative practitioner is to sharpen their ears to alternative stories, events that do not fit the dominant storyline, the ones that had not been strung together into stories and could contradict the self-defining ones. These events are called unique outcomes, actions on the part of the client that can be starting points in weaving alternative stories to live by (White and Epston, 1990).

These unique actions are the occasions, so often brushed aside as exception not worthy of attention, when, for example, Anger could not drive a father into verbal and physical aggression against his son upon hearing bad news from school, or when Fear could not coerce the son into cheating or running away.

These alternative stories are fragile at the beginning and are constantly in danger of being defeated by dominant ones, so every effort should be made to "thicken" the thin stories (Morgan, 2000) by giving minute details of the scene, the smell, the colours and feelings. Telling and re-telling the stories make them sturdier, while writing them down also contributes to a thick storyline.

The aim, however, is not to simply replace the dominant, problemsaturated stories with the desirable alternative ones, but instead to widen the landscape to encourage a rainbow of possible stories in place of the narrow 
perspective created by the problem. A multi-storied perspective opens space for negotiating a number of possible outcomes that were previously unthinkable.

\section{Deconstructing discourses}

White's philosophy was influenced by feminist authors and by the writings of Michel Foucault (Payne, 2006). He was intrigued by the ethics of power and the way it manifests itself in social discourses, in the taken-for-granted truths of institutions, religions, professions, clubs, neighbours and family members in all the strata of our lives. In any culture or society some stories have more power, more weight, than others. These cultural stories or discourses demarcate the lives and accepted behaviour of citizens, who perceive them as 'facts' or 'reality' (Freedman \& Combs, 2002).

These norms and narratives can be in contradiction. The masculine narrative of real-men-do-all-they-can-for-their-loved-ones can be in serious conflict with society's demand to respect property. So many men have been incarcerated for taking up crime to provide for their families, especially in dire situations like serious health problems.

Cultural discourses within smaller communities could also generate personal dilemmas. For example, the strict prison code of NTA (Never Trust Anyone) is against the strong desire and need to belong to somebody and have friendships to sustain integrity in hardship. Our lives are full of these dilemmas and discrepancies. Consider the traditional religious beliefs versus the demands of a modern woman or the dilemma between cultural integration and maintaining a homogeneous family unit.

Assisting clients to identify and describe these many dominant narratives (voices) is one of the main tasks of the practitioner. Only by doing so can she or he select the ones worthy of attention in any setting (Winslade \& Monk, 2000). Once the discourse becomes evident, it is possible to deconstruct, analyse and reconsider the nature and impact of this narrative. 
Deconstructing the dominant social discourses is the first step to liberate oneself from their power. Historically, psychology, and especially psychotherapy, have been complicit in maintaining and even strengthening these discourses. Narrative practices question them first by acknowledging their presence and second by purposefully seeking out and reflecting on marginalised or alternative narratives. In practice, it means that practitioners acknowledge that they cannot be completely neutral in their dealings and that the client knows more about their own life (White, 1995).

Discourses affect individual lives as well as professional beliefs. It is, for instance, a strong social narrative of the mediation profession that people are driven by their needs and the clash of these needs result in conflicts. Thus, according to the problem-solving approach in mediation, therapists must be "neutral" and "impartial" to negotiate between these needs (Winslade, et al., 1998). Winslade and Monk, mediators whose practices are informed by narrative ideas, criticise both the problem-solving approach of mediation practices and the need for - not to mention the possibility of - neutrality and impartiality on the part of practitioners.

Winslade and Monk have developed a new conflict paradigm (Winslade \& Monk, 2000). They have moved towards a notion that conflicts are embedded within differences of social discourses. According to a social constructionist view, there is no single true version of an event, only different perspectives. People make meaning of the world according to their experiences, which inevitably vary, and these meanings form the stories they tell about any event. These distinct stories, and the meanings given to them, are unique and therefore unavoidably create the potential for conflict (Winslade \& Monk, 2000).

This shift in perspective liberates the conflicting parties from their fixation on the problem itself, thus providing the opportunity for understanding the larger social context. The process of deconstructing their respective narratives helps them to reconsider how they view themselves and the other (Winslade \& Monk, 2000). For example, once a divorced father realises that acting as the 'traditional 
head of the family' is not the only or best way to pass on his values to his son, he can see himself engaging in a meaningful relationship with his child. As a result, time spent together can become more significant to each of them. This shift may in turn change his relationship with his ex-partner.

\section{Externalisation}

Since the $18^{\text {th }}$ century the notion of internalised problems has become the norm; we refer to people as bad-tempered, shy, weak, or aggressive as a complete description of their personalities and behaviours. The person becomes an object, a mere container of problems. These problems are difficult to solve and require the knowledge and skills of an expert. The problem-solving process will be long and the outcome hard to predict (White, 1995).

Narrative therapy, however, rejects the attempt to locate the problem within the person.

Michael White's most-quoted maxim is "The person is not the problem, the problem is the problem" (White, 1988/9; White \& Epston, 1990). Adhering to this maxim, the therapeutic conversation is conducted in a way that problems get externalised, personified and talked about as if from a distance. Externalising conversations has a unique language in which problems to be objectified are used in their noun form instead of as adjectives. Narrative practitioners talk about "the anger" rather than "angry" to personify the problems and so give them intentions and power of their own. Problems can be talked of as vicious, evil or just mischievous, detached from the disputing parties, almost like creatures that make people's lives difficult.

Naming the problem is a process that tempers their impact on the people and reduces the intensity of the conflict. In fact, this could be the first agreement in addressing a conflict, bringing a measure of unity without the threat of having to give up positions. Having established a common name for the disagreement, there is an opportunity to explore its history and its effects on the relationship 
between the parties. Practitioners can ask questions about what the problem or conflict destroys, hinders, makes difficult or even what it makes possible (Winslade \& Monk, 2000). Talking, for instance, about jealousy, as a monster that destroys intimacy, ruins the best moments, and brings about anger and desperation, makes it easier to talk about its effects without accusation and the consequent defensiveness. Also, jealousy not only affects the person one is jealous about, but the jealous person as well. It might whisper irrational things into her or his ear or distract the person at work. By inviting jealousy into the therapy room, it is easier to face it together, help overcome its toxic effect, and see the other person and the relationship without its devastating control.

It should be noted, however, that, externalisation is not merely a technique, it is an attitude, a way of looking at the world. The aim is to see the problem separate from and not as defining the person. Working with a family with a history of abuse, for instance, the therapist might inquire about the "reign of aggression", the "debilitating power of fear" or the "deceiving nature of silence". Conducting the therapeutic conversation with this mindset, parties come to understand the effect a problem might have on others and determine how to confront and resolve the problem (Freeman, et al., 1997).

Let me give you a short excerpt from a family consultation:

Father (about his young adult son, who is in trouble for vandalism): I can understand him. I was like him. It runs in the family. When I was his age I smashed and broke and saw no God no Human. Like an animal. Like a man.

Practitioner: You mean, it was difficult to control your anger?

F: It was no anger. It was like a wild beast. But sure, it was difficult to control. It's in me. I am that beast... Less so now.

P: How is that? How can you control that wild beast more these days?

F: Dunno. I suppose I got older, wiser ... maybe tired ... and suppose, I just can't. Not with the little one (his grandson) around. I've got to look after him. Can't let him down. 
P: So, you think it might be love or responsibility that could put the rein on that wild beast.

F: Those for sure.

Mother: (turning to her son) I could see no wild beast in your eyes.

Son: Maybe you don't, but I feel it...

The practitioner could have chosen to initiate a conversation about the story or narrative of what it is to be a man because that is part of how the father understands his son. Instead, she chose to externalise the idea of anger. She initiated a name to encourage the christening and carried on with the externalising language. It struck a chord with the son, who could feel understood, but still responsible. It opened up the possibility of considering the skills and knowledges that could help him control his own beast. Much later, having externalised the notions of anger, responsibility and tenderness, it was easier to discuss the social expectations (narrative) of masculinity.

\section{Collective narrative practices}

Narrative therapy has also turned away from the practice of isolating people with problems. Recognising that problems are embedded in the culture, a narrative approach involves members of the relevant communities to support the process.

In collective practices, it is paramount "to listen for both individual and collective speech patterns" (Denborough, 2008 p23): whenever there is trauma there is always a social issue. Practitioners therefore respond to both the individual and the collective issues. In their view, attending to a greater social problem often plays a considerable part in healing the individual (Denborough, 2008). For instance, in the comment: "When I was a kid, I was never much regarded as a human being in my family. I was a girl and fathers, of course, want boys" it is possible to detect the personal story of the speaker's role in her family as well as the collective, the social discourse, of 'boys being more valuable' than 
girls. Bringing the collective into focus can be genuinely empowering (Denborough, 2008).

Narrative practices, although part of a therapy tradition, demonstrate the extraordinary potential of engaging the community - the collective - in addressing an individual problem. This - the community - is the very place where restorative practices take their roots.

\section{Restorative practices - some history}

In ancient times, the practice of victims and offenders settling their disputes with help from their community was widespread. Crime was not considered an act against society. These cultures acknowledged that the participants - victims, offenders, their families and their immediate communities - were all affected by the crime and therefore must be involved in restitution. This is not to say that there were no rules to compensate for wrongdoings, but the aim of these rules was to reclaim an atmosphere of peace, wholeness and companionship in the community. Codes of Hammurabi, Roman Law, German tribal laws or the traditions of indigenous people of North America, New Zealand and Australia were all similar in that they were less punitive than restorative (Van Ness $\&$ Strong, 2010).

As kingdoms replaced tribal cultures, rulers took the place of victims; crimes were committed against the 'crown'. Punishment was meted out by the ruler and restitution or fines were paid to the state. The real victims were left out of the process. Although the failures of the system became apparent and prison reformers tried repentance, work treatment, training, psychological and mental treatments of the offenders, the victims were never again thought worthy of including (Van Ness \& Strong, 2010). It was not until the 1960s and ' 70 s that victim rights groups began to mobilise.

Nils Christie, a Norwegian criminologist, considered criminal acts as conflicts and thus unavoidable elements of society. He argued that these 
behaviours should be cherished, their solutions should not be monopolised by institutions, but rather be given back to the parties in conflict (Christie, 1977), an idea that is compatible with the perception of conflict as "the almost inevitable by-product of diversity" (Winslade \& Monk, 2000, p. 41). Winslade and Monk also want to give back the conflict to the participants by encouraging them to name it, make meaning of it, realise and deconstruct the social discourses giving the conflict its strength.

Christie (1977) called for the de-institutionalising of criminology; not unlike narrative theorists urging practitioners to step aside as experts and encourage individuals and communities to take responsibility for addressing problems. He described his vision of a victim-oriented criminal system that takes its format after neighbourhood courts, a system where response to crime is decided by those who are most closely affected by it and governed by the values of the community.

Soon research and experiments resulted in the introduction of interventions premised on the understanding of "crime as a wound within the community and recognise(s) that justice requires not just accountability but also healing" (Umbreit $\&$ Armour, 2011). Restorative J ustice as it evolved is not a scheme or a set of techniques but - much the same as Narrative practices - a world view, a perspective on human contact and especially conflict (Umbreit \& Armour, 2011). It is a dynamic and often controversial domain of beliefs and practices trying to find its way between being part of the system of law and justice and a social movement (Walgrave, 2011).

\section{Restorative justice programmes}

The three principal restorative justice initiatives are victim-offender mediation (VOM), conferencing and circles. The four essential values of all restorative justice programmes are:

- Inclusion - making sure that all affected parties are included (victims, offenders, their respective families and the larger community). 
- Encounter - a face-to-face meeting of the participants in a secure environment (when and where it is feasible);

- Amends - the offender taking responsibility for harm done and for restitution or compensation; and

- Reintegration - providing an opportunity for those responsible for causing harm to return to the community (Van Ness \& Strong, 2010).

VOMs are guided face-to-face meetings between victims and offenders and maybe the support persons of both parties - in a safe setting after thorough preparation by the facilitator. The name is somewhat misleading as the aim of the encounter is not - as is true in most mediation interventions - to come to a consensus acceptable by both parties. Instead, the process provides an opportunity for reconciliation, where victims gain confidence over their vulnerability and find a measure of acceptance and peace, and offenders realise the full effect of their behaviour and accept responsibility for the impact of their actions.

An ideal outcome of VOM is not necessarily compensation or restitution but psychological changes in the victim and the offender in relation to the criminal act. The story of the crime can be re-authored by the participants to create a narrative that is coherent and reflects their new perspectives on the events of the crime.

Family conferencing was first introduced in New Zealand to save young offenders from prison and is now widely used in several countries. The principal goal of this process is to preventing the criminalisation of vulnerable youth. The offender's extended family, together with other willing community members, are invited to discuss and determine how to share tasks and responsibilities that address the offender's behaviour, pooling their resources. Experts are not part of the conference but can be asked to provide answers to questions from group members to assist the group in making decisions.

Circles are facilitated discussions about harm or conflicts concerning a community. They can be held after sentencing to aid reconciliation (peace-making 
circles) or in place of sentencing (sentencing circles). In recognition of traditional methods, some judicial decisions in Canada have been transferred to traditional first nation communities (Bradshaw \& Roseborough, 2005).

\section{A possible synergy}

Narrative and restorative practices share common principles as well as some history:

- importance of stories;

- rejecting the expert position of professionals;

- significance of communities;

- inviting communities and individuals to own their conflicts and stories;

- relying on the wisdom of traditional cultures in problem-solving;

- rejecting blaming the individual and searching the broader social landscape for explanation and influence;

- acknowledging the simultaneous existence of contradictory stories and accepting them; and

- seeing conflict as essential, something that can have value.

Restorative justice aims for justice that entails healing, while narrative therapy "has the capacity to channel the energy arising from individual troubles and shape it into productive social action" (McLeod, 2006, p. 207). Thus, combining the two movements, that come from two directions and occupy overlapping territories could intensify their effect.

There are two areas where use of a combination of restorative and narrative practices could be beneficial to both approaches. 


\section{1) Interface between restorative justice and the criminal justice system}

Most restorative justice programmes take place within the court context. Thus, it is no surprise that it has been strongly influenced by the values and practices of the legal system, leaving little room for alternative outcomes apart from apology, disclosure and amends. Offenders' stories are often labelled "comfort stories" by practitioners, meaning they are formed to make excuses to ameliorate responsibility (Booth, 2018), while victims' stories are also often limited to satisfy social beliefs about victimhood (Pemberton et all, 2018).

J enkins (2009), who combines restorative and narrative ideas in his work with men who have abused, encourages practitioners to challenge the initial, often one-sided, self-deprecatory or self-important abusive self-narratives of the offenders and listen for signs of ethical qualities which they can use as openings to develop a fuller, multi-storied narrative less governed by the often-confining social discourses of masculinity (J enkins, 2006).

The danger of accepting culturally constructed narratives - those deemed consistent with the norms of the legal system - as the only truth about a person, applies to victims' stories as well. Narratives of offenders and victims are connected by the stories of crime, but the meanings of crime differ considerably for victims, offenders and the legal system (Decraemer, 2014). Complying with norms of criminal justice can result in one-sided storylines that emphasise vulnerability and guilt, leaving little room for self-definition or strength. It is the responsibility of the practitioner to find the unique outcomes that can lead to alternative stories and provide space for therapeutic change (White, 2007).

Whether offenders and victims can share their stories, and when, should be decided by the practitioner in consultation with all affected parties. Victimoffender mediation commonly starts with thorough preparation performed in alternating separate meetings with the victim(s) and the offender(s). The aim of the preparatory phase is to build trust with the mediator and the process, 
decrease anxiety and prepare the participants to see, hear or simply be in the presence of the other (Mercer \& Madsen, 2015).

Narrative techniques could be considered in this preparatory phase. As part of the narrative process, the participants could discuss and negotiate the meaning of experiences such as pain, loss, and violence. In the process of deconstructing these terms, the victim and offender can revise the isolating discourses and thereby assert a measure of control over their stories. With thorough preparation, there is every possibility that it can turn out to be a life-changing event.

\section{2) The role of communities in restorative justice practice}

In restorative justice, community members play a variety of roles, including the active and direct involvement of immediate family members of victims and offenders, concerned community members at peace-making circles, and the dedicated work of volunteers (Rossner \& Bruce, 2016). I argue that restorative justice as a movement, as well as a form of practice, could benefit largely from the tested and proven methods of collective narrative practices. One of their many advantages is that they rely on the strengths, traditions and cultural norms of the communities themselves.

The underlining principle of collective practices is the importance of telling and re-telling of life-stories - the narratives that create the ever-changing identities of persons. Re-authoring culturally defined stories needs audiences, stories need to be told and heard and then they can be profoundly life-changing (White, 2007). The first narrative technique that used audiences to absorb and respond to stories is outsider witness practice, which is rooted in the work of American anthropologist Barbara Myerhoff:

"Definitional ceremonies deal with the problems of invisibility and marginality; they are strategies that provide opportunities for being seen and in one's own terms, garnering witnesses to one's worth, vitality, and being." (Myerhoff 1982, p.267) 
Outsider witness practices build on the power of acknowledgment. The highly-structured ritual is divided into three stages:

1. Telling of the life-story by the person the ceremony is organised for;

2. Reflection in response to this story by the witnesses - by answering specific questions; and

3. Reflection by the person the ceremony is organised for, on how his or her story influenced the witnesses.

Outsider witnessing is a widely-used technique not just in community work but in therapy or mediation and it could be a powerful tool in the hands of restorative practitioners in the aftermath of harm done to the community.

Other collective practices can be used, such as sharing stories of knowledge and achievements between communities, the 'tree of life' technique that uses the metaphor of the tree to find and build on the roots and strength of communities experiencing hardship, the 'collective timelines' technique to highlight shared sentiments between people of very different backgrounds, and the power of songwriting and music. These methods have been developed in a variety of cases and used when crime or incarceration affected a community (Denborough, 2008).

\section{Conclusion}

This article identified many similarities in the underlining principles of narrative and restorative practices and suggested ways of combining the two practices in criminal cases.

Narrative techniques and methodologies that could be used within the framework of restorative justice include externalisation, spotting unique outcomes to weave alternative stories, re-authoring stories to gain multi-storied identities, and a great variety of collective narrative practices that could enhance the effectiveness of restorative justice. Narrative practitioners on the other hand 
could venture more in the territory of restorative practices - especially in criminal cases in judicial settings.

Greater awareness of the similarities between the two approaches is needed and could be achieved, in part at least, through conference and journal contributions from both sides. I urge restorative and narrative practitioners to test the ideas for cross-fertilisation outlined in this article and to develop programmes drawing on both sets of practices for the benefit of victims, offenders and communities.

\section{References}

Booth, M. (2018) in a blog of the film Inj ustice (http:// www.injusticefilm.com/2018/ 06/23/ michaela-booth-on-victims-and-redemption/ )

Bradshaw, W. \& Roseborough, D. (2005) Restorative justice dialogue: The Impact of Mediation and Conferencing on J uvenile Recidivism, Federal Probation, 69(2), p. 15-21. Available at: http:// ir.stthomas. edu/ssw pub/24 (Accessed: 15 May 2018) Christie, N. (1977) Conflicts as property, The British J ournal of Criminology, 17(1): 1-15.

Decraemer, K. (2014) Working with (Young) Offenders, Conference notes, Third Europe+Conference of Narrative Therapy and Community Work, Iasi, Romania Denborough, D. (2008) Collective Narrative Practice - Responding to Individuals, Groups and Communities who have Experienced Trauma, Adelaide: Dulwich Centre Publications.

Denborough, D., J . Freedman, and C. White (2008) Strengthening resistance: The use of narrative practices in working with genocide survivors, Adelaide: Dulwich Centre Foundation.

Freedman, J ., and G. Combs (2002) Narrative therapy with couples ... and a whole lot more! Adelaide, S. Aust.: Dulwich Centre Publications.

Freeman, J. C, D. Epston, D. Lobovits (1997) Playful Approaches to Serious Problems: Narrative Therapy with Children and Their Families, New York: W.W. Norton. 
Ganem P., D. Duncan (2017) Integrative Restorative J ustice Narrative Mediation circle Approach: Students' Perspective of their MSW Program Experience, Available at: https:// csus-

dspace. calstate. edu/ bitstream/ handle/ 10211.3/ 189850/GanemDuncanRJ NMcThesi s. pdf?sequence $=1$

J enkins, A. (2006) Shame, Realisation and Restitution: The Ethics of Restorative Practice, Australian and New Zealand J ournal of Family Therapy, 27(3), p. 153162.

J enkins, A. (2009) Becoming Ethical: A Parallel, Political J ourney with Men who have Abused, Dorset: Russel House Publishing.

Kecskemeti, M. (2013) Competent Students and Caring teachers: is a Good Pedagogy Always the Best Pedagogy? Teachers and Curriculum, Vol.13: 93-98. Kecskemeti, M., K. Kaveney, S. Gray, W. Drewery (2013), A Deconstructive Approach to Class Meetings: Managing Conflict and Building Communities, Narrative and Conflict: Explorations in Theory and Practice 1(1): 3051.

McLeod, J . (2006) Narrative thinking and the emergence of postpsychological therapies, Narrative Inquiry. 16(2006) pp. 201-210.

Mercer, V., K. Sten Madsen, M. Keenan and E. Zinsstag (2015) Sexual Violence and Restorative J ustice: A Practice Guide, Leuven Institute of Criminology. [online] Available at: http:/ / www. euforumrj.org/ wp-content/ uploads/ 2015/ 09/ DoingRestorative-justice-in-cases-of-sexual-violence_practice-guide_Sept2015-1. pdf (Accessed: 15 May 2018)

Morgan, A. (2000) What is Narrative Therapy? An Easy-to-read Introduction, Adelaide, S. Australia: Dulwich Centre Publications.

Myerhoff, B (1980) Number Our Days, New York: Simon and Schuster.

Myerhoff, B. (1982) 'Life history among the elderly: Performance, visibility, and remembering' in Ruby J. (ed.) A crack in the mirror: Reflexive perspective in anthropology, Philadelphia: University of Pennsylvania Press.

Payne, M (2006) Narrative Therapy, Sage Publications.

Pemberton, A., P.GM. Aarten, E. Mulder (2018) Stories as property: Narrative ownership as a key concept in victims' experiences with criminal justice, Criminology and Criminal J ustice [online]. Available at: 


\section{http:// journals. sagepub.com/doi/ 10.1177/ 1748895818778320 (Accessed: 15 May}

2018)

Rossner, M and Bruce, J . (2016) Community participation in restorative justice: rituals, reintegration, and quasi-professionalization, Victims \& Offenders, 11(1) pp. 1-19. [online] Available at: http:// eprints. Ise.ac.uk/65067/ (Accessed: 15 May 2018)

Umbreit, M., M. P. Armour (2011) Restorative J ustice Dialogue: An Essential Guide for Research and Practice, New York: Springer Publishing Company. Van Ness D.W., K. H. Strong (2010) Restoring J ustice: An Introduction to Restorative J ustice, Routledge.

Walgrave, L. (2011) Investigating the Potentials of Restorative J ustice Practice, J ournal of Law \& Policy 36 [online]. Available at:

https:/ / openscholarship.wustl.edu/ law_journal_law_policy/ vol36/ iss1/ 6/ (Accessed: 15 May 2018)

White, M. (1988/9) The externalizing of the problem and the re-authoring of lives and relationships in White M. (ed.) Selected Papers, Adelaide, Australia: Dulwich Centre Publications.

White, M., D. Epston (1990) Narrative Means to Therapeutic Ends, New York: Norton.

White, M., D. Epston (1992) Experience, contradiction, narrative and imagination: Selected papers of David Epston and Michael White 1989-1991, Adelaide: Dulwich Centre Publications.

White, M. (1995) Re-authoring lives, Adelaide: Dulwich Centre Publications.

White, M. (2007) Maps of Narrative Practice, New York: Norton.

Winslade, J., M. Kecskemeti (2016) Better Classroom Relationships, New Zealand: NZCERPRESS.

Winslade, J., G. Monk, A. Cotter (1998) A Narrative Approach to the Practice of Mediation, Negotiation J ournal, 14(1), pp. 21-41

Winslade, J., G. Monk (2000) Narrative Mediation: A New Approach to Conflict Resolution, San Francisco: J ossey-Bass.

Winslade, J., M. Williams (2012) Safe and Peaceful Schools: Addressing Conflict and Eliminating Violence, Corwin. 
J udit Hajdu has been working as a psychologist with children, adults, couples and families for 15 years. She has been secretary to the Hungarian Family Therapy Association and has worked as psychologist and restorative practitioner at prisons. She was the initiator of prison radio in Hungary. At present, she studies criminology at the University of Glasgow. 